\title{
La democratización y el proceso electoral de 2000
}

\section{Reversibilidad de algunos procesos}

Hace ya varios años, cuando en la ciencia política comparativa estaba en boga el tema de las transiciones políticas, se decía que como resultado de un proceso de transición política podían haber diferentes produclos. En aquel entonces se decía que una transición política no necesariamente desembocaba en la instauración de un régimen democrático. De hecho, uno de los textos clásicos de la Ilamada "transitología" insinuaba esta afirmación en el título mismo de la obra: Transitions from Authoritarian Rule (Transiciones desde un régimen autoritario). Los compiladores de los cuatro volúmenes que constituyen dicha obra (Guillermo O’Donnell, Philippe C. Schmitter y Lawrence Whitehead, contratados para dicho fin por el Woodrow Wilson International Center for Scholars) fueron prudentes al sugerir que los procesos políticos que se estaban registrando en el mundo desde la segunda mitad de la década de los años setenta no eran necesariamente transiciones hacia la democracia, sino que transiciones desde el autoritarismo.

Por otra parte, la abundante literatura que aborda el tema de las transiciones políticas también insistió en que los nuevos regímenes instaurados en la "tercera ola democratizadora" pronto comenzaron a enfrentar problemas de estabilidad y persistencia. Se pensaba que la instauración de un régimen democrático (allí donde éste era tal) no era necesariamente un proceso irreversible. De hecho, Samuel Huntington registra en su obra The Third
Wave (La tercera ola), ya en la década de los años noventa, cómo las anteriores "olas democratizadoras" habían tenido sus propias "contraolas" y que, por tanto, era de esperar que la "tercera ola" tuviese también su "contraola". En otras palabras, se afirmaba que las democracias recién instauradas enfrentarían pronto los problemas relativos a su consolidación. Muy recientemente, expertos de la Unidad para la Promoción de la Democracia de la Organización de Estados Americanos han advertido que la democracia en algunos países de América Latina es todavía muy frágil, afronta serios riesgos y nada garantiza su plena vigencia!.

Tres problemas importantes señalados por los transitólogos eran (a) superar los legados del régimen autoritario anterior; (b) lograr la eficacia procedimental, entendida como buen funcionamiento de las instituciones, y (c) lograr la eficacia, en términos del rendimiento o implementación de políticas públicas efectivas que satisfacieran las principales demandas de la ciudadanía. De la superación de estos problemas dependía, en buena medida, la persistencia (como mínimo) de los regímenes recién instaurados. De la forma cómo se superaran estos problemas dependería la cualidad y calidad de los nuevos regímenes. Aun cuando pudiesen calificarse algunos como democráticos, muy pronto se insistió también en la diversidad de democracias que habían resultado de los procesos de transición. El uso de los adjetivos se puso de moda en la literatura sobre las nuevas democracias. Pero no se trataba solamente de la vieja dis-

1. "En América Latina la democracia aún es frágil", La Prensa Gráfica, 19 de febrero de 2000. 
cusión entre democracias participativas versus democracias representativas. Se trataba más bien de nuevos tipos de "democracia", que necesitaban un tratamiento y una caracterización específicas.

Uno de estos nuevos tipos (o "animal" como lo llamó su autor Guillermo ODonnell) es la llamada democracia delegativa. Al comienzo de la década de los años noventa del siglo pasado, O’Donnell tenía como referentes para analizar a este nuevo "animal" a los regímenes instaurados, en la década de los años ochenta, en Argentina, Brasil, Perú, Ecuador, Bolivia, Filipinas y Corea del Sur. Los gobiernos de estos países compartían algunas características que le permitían a ODonnell considerarlos como pertenecientes a un tipo específico de democracia. Entre estas características sobresalen dos. En primer lugar, la fuerte presencia del presidente como encarnación del interés nacional, muy por encima de otros poderes como el congreso y el poder judicial, a quienes ni siquiera debería rendir cuentas de su acción de gobierno; $y$, en segundo lugar, la debilidad misma de todo el entramado institucional, que supone la plena vigencia del Estado de derecho.

Más que detenerme en una presentación exhaustiva de la caracterización que hace ODonnell de las democracias delegativas, todas las ideas contenidas en los párrafos anteriores tienen la intención de llamar la atención sobre una serie de problemas a los que se ven avocados los regímenes que surgen de una transición desde el autoritarismo. En la medida en que los acuerdos de paz, que pusieron fin al conflicto armado interno en el que El Salvador se vió envuelto desde 1981 hasta 1992 , constituyen la aceptación de unas nuevas "reglas del juego político" por parte de los principales actores de aquel conflicto, dichos acuerdos constituyeron la aceptación del diseño institucional para el nuevo régimen político que desde ese momento se instauraría en El Salvador. La ejecución de los acuerdos de paz, entre 1992 y 1994 , culminaron con la instalación de las primeras autoridades políticas elegidas democráticamente en el país. Entre tales autoridades estaban el presidente y vice-presidente de la república, los 84 diputados de la asamblea legislativa, los 20 diputados al parlamento centroamericano y los miembros de los 262 concejos municipales. Para algunos analistas, nos encontrábamos en un momento de fundación de la democracia salvadoreña.

\section{2. ¿Agotamiento del entramado institucional?}

Pasada la euforia, el nuevo siglo nos encuentra con los problemas no solo de la consolidación de la democracia independientemente del adjetivo que lleve æcuya determinación puede ayudar a comprender algunos de esos problemas, pero que no realizaré en este lugar. Un análisis "frío" de lo que ocurre a nivel de régimen político podría sugerirnos que hemos entrado en una fase de agotamiento de la institucionalidad, creada con los acuerdos de paz. La percepción de una tal situación se agrava si consideramos que el cambio político en El Salvador ocurre simultáneamente al cambio económico, es decir, al cambio en "las reglas del juego" para los diferentes actores económicos, especialmente el Estado. Señalar este hecho es importante, porque nos advierte sobre la fuente de nuevos problemas que se agregan a los propiamente derivados del proceso político y a los que hice referencia en un párrafo anterior.

Los cambios en la economía y la política nacionales no deben verse fuera del contexto del proceso de cambio social que, desde la década de los años sesenta, viene desplegándose a nivel mundial y que algunos han dado en llamar globalización e incluso surgimiento de un nuevo tipo de sociedad. Un cambio análogo al del surgimiento de la sociedad moderna. De la inserción a este proceso mundial han surgido otros problemas adicionales a los que he venido considerando hasta el momento. Uno de los más importantes problemas tiene que ver con la disminución de la capacidad del gobierno para dictar autónomamente su política económica frente a la presión de organismos internacionales como el Banco Mundial y el Fondo Monetario Internacional. ¿Estaban en la mente de los negociadores de los acuerdos de paz las dinámicas generadas por todos estos procesos simultáneos? ¿Garantizaba la plena implementación de dichos acuerdos una paz negociada sostenible en el tiempo?

No es mi intención culpar o exculpar a nadie en este comentario. Además, escribir estas líneas una vez que conocemos lo que han dado de sí los acuerdos de paz supone una ventaja para el comentarista. Lo que me interesa es llamar la atención sobre lo complejo que son los procesos que nos ha tocado vivir en este principio de siglo. Especialmente me interesa proponer una reflexión sobre cierta manera de leer los acontecimientos, que parece estar presente en analistas y dirigentes 
políticos y económicos. Me refiero a una vieja tradición en las ciencias sociales con raíces en la biología: el evolucionismo sacial. No me guía un interés estrictamente académico, pues no creo que éste sea el espacio y ésta la forma adecuada para discutirlo. Me orienta más bien una preocupación las consecuencias que tal lectura puede tener.

Para el evolucionismo (clásico, sobre todo) las sociedades avanzan inexorablemente de estadios 0 fases inferiores a estadios o fases superiores. Se trata de un proceso lineal de desarrollo, en el que una vez que se ha superado una etapa no hay marcha atrás, no hay posibilidad de retorno. En la medida en que la humanidad es considerada como una sola, aunque distribuida a lo largo y ancho de la tierra, se supone que todas las sociedades recorren el mismo "camino". Estas premisas están en la hase de teorías como la de la modernización y en planteamientos relativos al desarrollo. No resulta contra toda lógica que tales premisas también sustenten teóricamente las políticas públicas que desde algunos centros decisores internacionales se dictan a los países "en vía de desarrollo". No voy a entrar en una discusión que, ya en los años cincuenta y sesenta del siglo pasado, produjo abundante literatura, en términos de polémica.

Queriéndolo o no, conscientemente o no, en nuestro país no resulta infrecuente encontrarse con lecturas y explicaciones del proceso político en tales términos. Pensar que la instauración de un nuevo régimen político a partir de los acuerdos de paz es todo lo que el país necesitaba para pacificarlo no sólo no toma en cuenta que hay que consolidar ese régimen, sino que también pasa por alto el riesgo de una posible regresión. Para buscar la primera y evitar la segunda, se necesita estar plenamente consciente y tener la voluntad política necesaria (con una alta dosis de coraje) para actuar en esa línea. Pero, ¿están nuestros políticos a la altura de estos desafíos?

Si uno mira hacia atrás en el tiempo, no puede negar que ha habido avances en materia política. De hecho, es lo que podía esperarse como resultado de un proceso político como la negociación para poner fin a un conflicto armado. Creo que en este punto no hay que engañarnos. El diálogo y la negociación desembocaron en unos acuerdos que posibilitaron la instauración de "nuevas reglas de juego", caracterizadas fundamentalmente por la no exclusión de actores políticos importantes. Es la inclusión de quienes estaban excluidos de los pro- cesos de toma de decisiones políticas lo que no hay que perder de vista en el análisis de la dinámica derivada de los procesos de diálogo y negociación. Es este hecho el que subyace a los acuerdos alcanzados y a la preocupación posterior por su implementación. Esto no tiene nada de bueno ni de malo. Se trata de una lógica política, que no necesariamente tiene por qué ser ética. Considero que este planteamiento no debe ser pasado por alto al analizar el proceso político desde 1994 hasta la fecha. Porque și bien se registraron avances en términos de no exclusión política hay suficientes indicios de que ha ocurrido o bien un estancamiento o bien vamos de retro. Si esto fuera cierto, resultaría entonces que la lectura y las actitudes "evolucionistas" han sido erradas. Tal vez estemos a tiempo para leer las cosas en otra clave y actuar en consecuencia.

\section{El juego político electoral}

Uno de los ámbitos que permite identificar un estado de agotamiento de algunas dinámicas introducidas por los acuerdos de paz es el del juego político electoral. Y aquí podemos detenernos a contemplar lo que ha ocurrido en términos de participación de la ciudadanía en las elecciones, la actividad de los partidos políticos y, muy especialmente, el desempeño del Tribunal Supremo Electoral (TSE).

\subsection{Participación electoral}

Desde 1994 a febrero del 2000 se han celebrado tres procesos electorales (1994, 1997 y 1999) y actualmente estamos metidos en la realización de un cuarto proceso (tercero de elección de diputados y concejos municipales). A nadie que le haya seguido la pista a todos estos procesos se le escapa que una de las notas sobresalientes de los mismos ha sido el aumento del ausentismo por parte de la ciudadanía. Un ausentismo que, según diferentes encuestas de opinión pública, tiene como causa la apatía y el desinterés de la población por todo aquello que "huele" a política. Esta apatía y este desinterés se basan en la percepción cada vez más generalizada de que, o bien de nada sirve votar o participar en política, porque todo sigue igual o peor, o bien porque "todos los políticos son iguales". En relación con la probable participación en las elecciones de marzo de este año, las encuestas de opinión parecen sugerir una vez más unos niveles de ausentismo cercanos al 50 por ciento o más. No ahondaré en este punto, puesto que ya habrá tiempo para ello después de las elecciones. Nada 
más me interesa dejar constancia de que hasta la lecha, en términos de participación electoral, hay una tendencia, desde 1994, a la disminución, a la desmovilización del electorado.

Si nos atenemos a las cifras de participación electoral que se vienen registrando desde 1982, año de elección de la Asamblea Constituyente que redactó la Constitución Política vigente, la participación electoral en 1999 fue la más baja desde entonces. Si luego hacemos de las elecciones presidenciales de 1984 nuestro "mojón" de referencia, resulta que la tendencia a la baja en los niveles de participación viene desde entonces. En 1984, la participación rondó el 80 por ciento, mientras que en 1999 rondó el 40 por ciento. Este comportamiento debería ser preocupante para los partidos políticos y el Tribunal Supremo Electoral por cuanto ellos son los otros actores del juego político electoral. La clientela se está alejando del mercado político. Esta situación podríamos interpretarla como agotamiento procedimental. Una vez pasadas las elecciones del próximo mes de marzo, podremos decir que en veinte años hemos tenido diez procesos electorales. Entre 1982 y 1991 se jugó con el argumento de que las elecciones eran la solución para la guerra. Votar era considerado un acto de patriotismo para alcanzar la paz. Esta no llegó por vía electoral, sino por el diálogo y la negociación. Así las cosas, las elecciones no proporcionaban al electorado lo que los partidos (especialmente los que en su momento eran partidos en el gobierno) prometían: la paz.

Una vez alcanzada la pacificación, los partidos han venido proponiendo que al votar por ellos se resolverían los dos principales problemas que aquejan a la población: la inseguridad pública y la problemática económica (alto costo de la vida, desempleo, inflación, etc.). La tendencia a la baja en la participación electoral está asociada con la percepción de que estos problemas no se resuelven votando. Así, pues, el procedimiento electoral parece no dar más de sí. El esfuerzo de los partidos y candidatos, al igual que del Tribunal Supremo Electoral, para atraer a los electores potenciales probablemente refleja esta preocupación.

\subsection{El respeto de los partidos a las "reglas del juego"}

Al analizar a los partidos políticos en su balance político del año 1999, Proceso (Número 884) concluye que "las cosas están mal y seguirán mal". Si tomamos en cuenta lo dicho antes acerca de la posibilidad de reversión de los procesos políticos, podríamos parafrasear esa conclusión diciendo que "las cosas están mal y seguirán peor". ¿Por qué introducir este ligero matiz? Porque las cosas no sólo están mạl, sino que pueden estar empeorando. Por ejemplo, sabemos ya que en términos de candidatas a puestos de elección pública, especialmente a nivel de escaños legislativos, la participación de las mujeres ha descendido. El resultado lógico de esta situación es que, en términos de distribución por género, la Asamblea Legislativa que se elegirá en marzo tendrá una menor participación femenina. Desde una perspectiva de género, esta será una situación peor que la actual. Ahora habría que preguntarse si este proceso de disminución de la participación femenina en los puestos de elección popular ha sido un hecho consciente. De ser así, la cosa sería aún más grave.

También se percibe como peor o como sinónimo de detereoramiento de la institucionalidad creada en los acuerdos de paz el nivel de acatamiento de las reglas del juego por parte de los partidos. Por supuesto que esto tiene que ver también con la capacidad del Tribunal Supremo Electoral para hacer respetar las reglas. A ello me referiré más adelante. A nadie que haya seguido con atención la forma cómo se llevó a cabo la campaña propagandista de los partidos, se le escapa que los partidos ARENA y FMLN se colocaron por encima de las reglas. También lo hicieron otros partidos pero, por la notabilidad del caso, deseo referirme a los dos primeros. Además hay otra razón para enfocar el análisis en estos dos partidos. Fueron un gobierno de ARENA y una parte de la cúpula del actual FMLN los que suscribieron los acuerdos de paz. Su papel protagónico en este sentido es innegable. Quizá en este hecho haya que buscar una explicación a su actitud de sentirse por encima de lo normado en el Código Electoral. Sin embargo, hay algo más profundo y por ello menos evidente.

Un principio básico de todo régimen democrático consiste en la legitimidad de la que gozan las reglas del juego. La literatura politológica que en la década de los años setenta del siglo pasado trataba de explicar la quiebra de las democracias, enfatizaba las consecuencias que la pérdida de legitimidad podía tener para la pervivencia de un régimen. La "transitología" de la década de los años ochenta volvió a insistir en el papel de la legitimi- 
dad. Se decía entonces que el problema no estaría tanto en una disminución de la legitimidad del régimen, sino en el surgimiento de alternativas que gozaran de mayor legitimidad. Posteriormente, la literatura sobre la consolidación democrática insistió en que la clave de legitimidad de un régimen residía en que los actores políticos relevantes la considerasen como the only game in town (el único juego en la ciudad). ¿Qué tiene que ver esto con lo dicho sobre los partidos en el párrafo anterior?

El código electoral forma parte de las reglas del juego a las que deben someterse los partidos políticos. En este código está regulada la propaganda electoral que, si bien es un derecho que debe garantizarse, está sujeto a las limitaciones "que establecen las leyes de la materia, la moral y las buenas costumbres" (Art. 227). Además, según el Artículo 230 del mismo Código, "se prohibe a los Partidos Políticos o Coaliciones y a todos los medios de comunicación, personas naturales o jurídicas, hacer propaganda por medio de la prensa, la radio, la televisión, mítines, manifestaciones, concentraciones, hojas volantes, vallas, aparatos parlantes, así como la pinta y pega de la misma en lugares públicos, antes de la iniciación del período de propaganda que regula el Artículo 81 de la Constitución de la República [...]". El citado artículo de la Constitución establece que la propaganda para la elección de concejos municipales comienza treinta días antes de las elecciones. Como éstas se llevarían a cabo el 12 de marzo, antes del 12 de febrero estaba prohibido hacer propaganda. Esto es lo que establece la norma. ¿Qué fue lo que hicieron al respecto algunos partidos, especialmente ARENA y el FMLN? Colocarse más allá de esta normatividad, ignorarla.

No me interesa aquí el debate jurídico del asunto. Para eso están los expertos. Me interesa más proponer una interpretación sociopolítica de los acontecimientos, que no tiene por qué coincidir con el análisis jurídico. De hecho utilizamos lenguajes distintos. Partiré, entonces, del análisis sociológico sobre la legitimidad de un orden (que para nuestro caso se traduce en la normatividad electoral). Desde Max Weber se sabe que la legitimidad está basada en una creencia y un sentimiento. Por un lado, la creencia, por parte de los actores, de que si se actúa de manera diferente a to prescrito socialmente se pueden obtener perjuicios. Por otro lado, el sentimiento de obligatoriedad a cumplir con la norma, el sentirse moralmente obligado a cumplirla. A medida que disminuye la fuerza de aquella creencia y de este sentimiento, la legitimidad del orden se erosiona. Puede llegarse a un punto tal de erosión que algunos actores se salten la norma, no se sometan al orden establecido. No se sometan porque o bien no creen que su acción les puede acarrear perjuicios o bien porque no se sienten moralmente obligados. Así, pues, la eufemísticamente llamada pre-campaña para las elecciones de concejos municipales fue una manifestación o bien de que los partidos y, o candidatos no creían que podían ser castigados por incumplimiento de la norma (lo cual estuvo a punto de suceder, en el caso de la campaña de ARENA y del FMLN en San Salvador, pero que, efectivamente, sucedió en otros municipios y respecto de otros partidos) o bien que los partidos y, o candidatos no se sentían moralmente obligados a respetar, por encima de intereses partidistas, la normativa electoral (algo que no es del todo inverosímil, a juzgar por la tenacidad e insistencia de los participantes respecto a que su acción no era propagandística y a no acatar las "recomendaciones" y "advertencias" del Tribunal Supremo Electoral para retirar de los medios masivos de comunicación todo indicio de propaganda electoral).

La pre-campaña de los candidatos para alcalde municipal en San Salvador fue la más sonada y documentada, incluso a nivel de caricaturas, en algunos rotativos informativos de la capital del país. Pero no fueron los únicos casos de irrespeto a lo normado en el Código Electoral y la Constitución. Queda para quienes escriban la historia de este proceso electoral el documentar más las ideas aquí expuestas. Como dije anteriormente me interesa más hacer una interpretación sociopolítica del asunto. Sociológicamente hablando, estamos ante un problema de deterioro de la legitimidad de la normativa electoral. Desde una perspectiva de ciencia política comparativa, estamos ante un problema de debilidad institucional, o como vengo diciendo a lo largo de este comentario, de agotamiento de la institucionalidad surgida de los acuerdos de paz. Lo establecido en el Código Electoral en materia de propaganda no es suficiente para contener y controlar la acción de los partidos políticos. Estos han encontrado resquicios por donde evadir (saltarse) la norma. Si se me permite la comparación, diré que tenemos un depósito de agua con agujeros. Así que, en términos del comportamiento de los partidos políticos, ahora estamos peor que antes. Pareciera que ahora lo que interesa ya no es ate- 


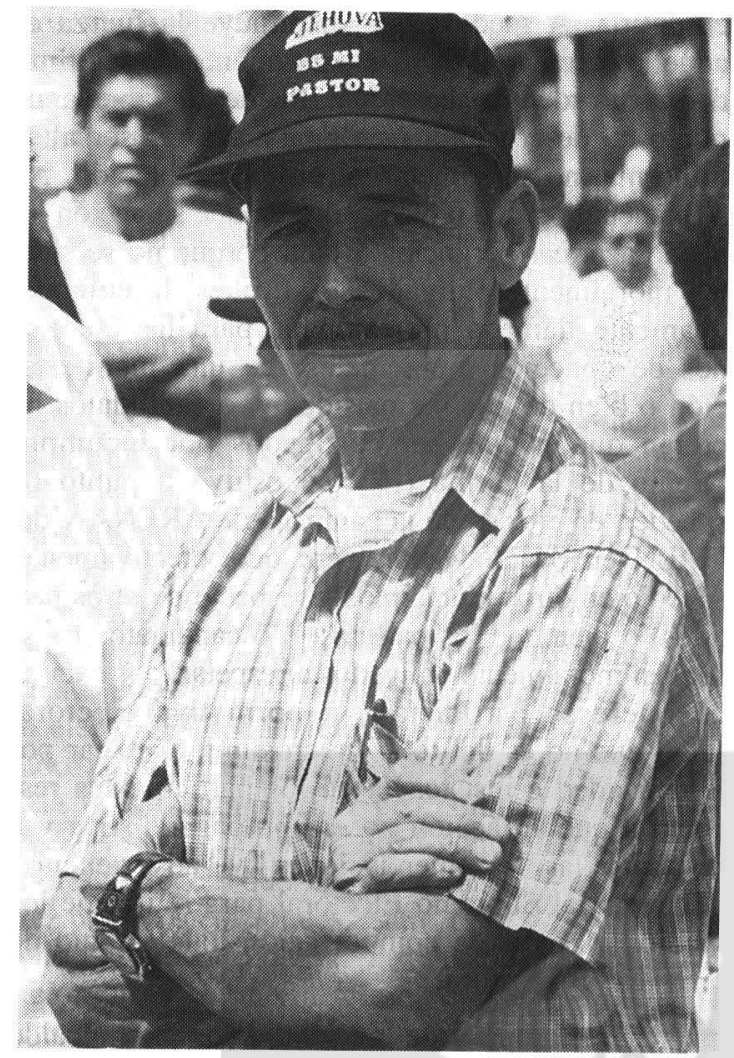

nerse a unas reglas del juego universalmente aceptadas, sino que buscar maneras cómo evadirlas, ignorarlas, adaptarlas o subordinarlas a la estrategia de lucha política para garantizar los intereses partidistas.

Por otra parte, las intenciones de algunos legisladores para introducir modificaciones a los periodos para los que son electos el presidente y el vice-presidente, los diputados y los concejos municipales también puede interpretarse como señal de agotamiento del diseño institucional que regula lales periodos. Al menos desde el punto de vista de aquellos legisladores y aunque ellos no hablen de un agotamiento. Pero, ¿qué significa el deseo de introducir reformas a leyes especílicas? Otra cosa es que se argumente con la conveniencia o no para la gobernabilidad, para la estabilidad y la continuidad de determinadas políticas que desde el gobierno nacional o municipal se estén implementando. Estos argumentos ya podrán ser discutidos en la ocasión oportuna.

\subsection{Las candidaturas independientes y las coa- liciones}

Aunque por el momento, esta temática ha sido puesta a un lado, nada nos dice que no volverá a surgir más adelante, una vez pasadas las elecciones del 12 de marzo. Si algunos ciudadanos lograron llamar la atención por sus intenciones de presentarse como candidatos a diputados, independientemente del apoyo político de los partidos, indirectamente se está sugiriendo que el marco de la representación política, sólo a través de los partidos, ha perdido legitimidad. Ha dejado de considerarse como the only game in town y se propone como alternativa mejor un diseño institucional diferente, que permita las candidaturas independientes. Ya vendrán entonces los debates sobre el nivel y la forma cómo serán aceptadas esas candidaturas. Probablemente, habrá que experimentar si no al nivel de escaños legislativos, sí a nivel de los concejos municipales. De hecho es lo que existe en países vecinos como Guatemala y Nicaragua. Como lo dije respecto de la iniciativa de reforma de los periodos establecidos para el ejercicio de los cargos públicos de elección popular, sobre el tema de las candidaturas independientes ya llegará también el momento adecuado para su discusión. Lo que me interesa resaltar aquí es que también desde esta temática llegamos al problema del agotamiento del arreglo institucional político electoral.

Por otra parte, entre los candidatos respaldados por algunos partidos políticos para estas elecciones hay "candidatos independientes" en el sentido de que no tienen un historial partidista que los acredite. En la literatura politológica, éstos reciben el nombre de outsiders. Justifican su participación en la intención de aprovechar el espacio que les brinda un partido para luego promover el deporte, la cultura, etc. Si los partidos tienen que recurrir a este tipo de candidatos es porque implícitamente se reconoce la necesidad de ampliar la representación de intereses a otros sectores no partidistas. Las "iniciativas ciudadanas" también podrían considerarse desde esta perspectiva. Siendo el resultado de alianzas entre partidos y organizaciones no partidistas, las candidaturas de tales iniciativas lambién ponen en evidencia el agotamiento de las formas de representación institucionalizadas.

Las diversas coaliciones pactadas para las elecciones de marzo próximo, tanto para la Asamblea 
Legislativa como para los concejos municipales, también pueden interpretarse a la luz de la argumentación básica de este comentario. Más de cuarenta coaliciones para la competencia municipal. Diversos partidos buscan agenciarse de esta manera alguna presencia en los concejos municipales. En otro lugar he comentado que, en parte, esto es debido a la fuerza de la lógica que impone el sistema electoral de mayoría simple, utilizado para el reparto de los 262 concejos municipales. Como dicho sistema funciona con la lógica de que quien gana se lleva todo, una forma para intentar obtener participación en el gobierno municipal es por medio de un pacto pre-electoral. Pero también podría lograrse por la vía de la reforma electoral, pasando de un sistema de mayoría simple a otro de representación proporcional. Cualquiera de las dos vías es válida. Ambas apuntan a una disconformidad implícita con el diseño institucional de representación actual.

\subsection{La máxima autoridad en materia electoral}

En el contexto del proceso electoral, que culminará con las volaciones del 12 de marzo, han ocurrido una serie de acontecimientos que ponen en duda quién es realmente la máxima autoridad en materia electoral en el país. Se supone y está normado en el Artículo 55 del Código Electoral que la entidad en la que recae dicha autoridad es el Tribunal Supremo Electoral. El Artículo 56 de dicho Código establece además que el Tribunal Supremo Electoral "es un organismo con plena autonomía, jurisdiccional, administrativa y financiera en materia electoral y por consiguiente, no supeditado a organismo alguno de Estado". En cierta forma, el Tribunal Supremo Electoral es "un cuarto poder". Ahora bien, el Artículo 59 norma cómo está integrado el Tribunal Supremo Electoral: cinco magistrados elegidos por la Asamblea Legislativa. Para elegir a estos magistrados, la Asamblea Legislativa toma en consideración ternas que presentan los tres partidos políticos o coaliciones con mayor número de votos, en la última elección presidencial (para llenar una cuota de tres magistrados) y la Corte Suprema de Justicia (para cubrir las otras dos plazas).

Los dos magistrados propuestos por la Corte Suprema de Justicia no deben tener afiliación partidista. Desde este punto de vista, estos dos magistrados son "independientes". Los otros tres magistrados son propuestos por los partidos y, aunque no se dice en el Código que pueden o no tener afiliación partidista, en la práctica, lo más probable es que sí tengan afiliación partidista. Con esta composición, matemáticamente, los partidos políticos tienen ventaja para controlar las disposiciones y acciones del Tribunal Supremo Electoral. Una primera pregunta que puede plantearse ante dicha composición va en la línea de los límites que puede tener la autonomía que le otorga el citado Artículo 56 del Código Electoral. La composición del Tribunal Supremo Electoral puede ser materia para una discusión jurídica, pero lambién puede serlo para una reflexión politológica. Desde este último punto de vista, la composición del Tribunal Supremo Electoral está sesgada para favorecer intereses partidistas frente a intereses no partidistas. Que el Tribunal Supremo Electoral esté orientado a velar por intereses partidistas por sobre no partidistas no quiere decir que se favorezca mecánicamente a un partido en concreto. En tal caso, habría que considerar los partidos específicos que tienen presencia en el Tribunal Supremo Electoral y sus posibilidades para realizar pactos en alguna materia, de tal forma que un partido se vea favorecido. Lo que quiero decir con la orientación partidista del Tribunal Supremo Electoral debe entenderse en relación a otros intereses de otros actores políticos. Entre estos "otros actores" sobresalen los electores.

Es cierto que individualmente los magistrados pueden estar interesados en hacer las cosas tomando muy en cuenta los intereses de los electores. Por ejemplo, la iniciativa para acercar las urnas a los votantes puede obedecer a una lógica de facilitar la participación de aquéllos. Sin embargo, en algún momento, cualquiera de los partidos con presencia en el Tribunal Supremo Electoral puede llegar a considerar que una mayor participación electoral puede acarrearle algunas consecuencias que no estaría dispuesto a asumir, porque atentaría contra algún interés vital del partido. Al plantearse una situación de este tipo habría una "riña de intereses": los intereses del electorado versus algún interés partidista. La pregunta lógica es, ¿cómo resuelve este conflicto de intereses un tribunal en el que una de las partes es a la vez juez?

Por otra parte, el control partidista del Tribunal Supremo Electoral puede provocar situaciones en donde no se trata de conflicto de intereses partidistas versus no partidistas, sino más bien de intereses partidistas versus intereses generales. La llamada "precampaña" electoral para concejos muni- 
cipales ha sido un escenario propicio para observar una situación de este tipo. Podemos suponer que el respeto a la ley, al orden jurídico establecido, es de interés general. Todos los actores particulares deben regular sus decisiones y acciones subordinando sus intereses particulares a este interés general para la buena marcha "del juego". Ningún actor en particular debería estar por encima de la ley. Para velar que todos los actores particulares cumplen la ley, los estados crean instituciones con esta función concreta. Estas instituciones constituyen una especie de árbitro, que controla el juego. Su autoridad la debe imponer desde el principio. De lo contrario, como en cualquier juego donde hay un árbitro que no logra imponer su autoridad, "el juego se le va de las manos". Al final, el juego puede terminar siendo un desastre o se pasa a una fase de apelaciones de parte de uno de los jugadores, para intentar "ganar en la mesa lo que no pudo ganar en la cancha". Consecuencia grave de esta situación es que el árbitro pierde autoridad no sólo frente a los jugadores, sino también frente a los espectadores. Dejando a un lado la metáfora del juego y los jugadores, a nadie escapa que, en materia de propaganda electoral, el Tribunal Supremo Electoral no pudo hacer valer su autoridad frente a algunos de los partidos políticos, especialmente aquellos con representante dentro del Tribunal. Aunque el Tribunal Supremo Electoral sancionó a los dos principales partidos en la disputa por la alcaldía de San Salvador, lo hizo prácticamente cuando faltaba una semana para que iniciara oficialmente la propaganda electoral. Uno puede preguntarse entonces, ¿por qué tardó tanto el Tribunal Supremo Electoral en sancionar a esos partidos? ¿Qué relación hay entre esa tardanza y el hecho de que dos miembros del Tribunal Supremo Electoral tengan vinculaciones partidistas? ¿Los intereses de quién o quiénes prevalecieron sobre el interés general de hacer valer la ley?

El "escándalo" de la utilización de la Imprenta Nacional para imprimir propaganda a favor de uno de los partidos daría también más argumentos para cuestionar a las autoridades públicas que tienen, entre otras, la función de velar por el cumplimiento de la ley. En este caso habría que hacer referencia a la figura del Fiscal Electoral. De nuevo, estamos ante una situación que puede ser interpretada en términos jurídicos sobre los cuales también ya habrá tiempo y espacio para ello. Pero también puede ser interpretada en términos politológicos y, en la línea argumental de todo este comentario, en términos de un agotamiento de un diseño institucional que regula el juego político electoral. Una cosa era discutir si la Imprenta Nacional estaba facultada para imprimir propaganda de un partido y otra cosa era discutir si un partido podía recurrir a medios públicos (estatales), a los servicios de la imprenta. Como era difícil negar que había ocurrido lo segundo, se desvió la atención al hecho de si la demanda de servicios para la Imprenta provenía del instituto político o si se trataba de una iniciativa personal del alcalde de San Martín. El Fiscal Electoral decidió esto último. Consecuencia a esperar en el futuro, una vez sentado tal precedente, es que cualquier partido podrá recurrir a una persona para que solicite la prestación servicios (indireclamente) a medios de comunicación como la Imprenta Nacional. Será cuestión de revisar quién tirmó el cheque o la órden de pago. No importará si con esa acción se ha favorecido a determinado partido. Vale entonces preguntarse, ¿no sería esta una forma de saltarse la ley? ¿No refleja esta situación problemas en el entramado institucional vigente?

Para no señalar únicamente debilidades del entramado institucional electoral, vale la pena señalar que algunas dinámicas positivas se han generado en el contexto de este "estira y encoge" entre el Tribunal Supremo Electoral y algunos partidos, entre intereses generales e intereses particulares. Algunos medios de comunicación de masas se hicieron eco de lo que estaba en juego. Ha habido un mayor seguimiento de la actividad de los partidos y del mismo Tribunal Supremo Electoral a través de los medios. Ello ha permitido que salten a la luz pública esle juego de intereses y la forma cómo se ha resuelto. La mayor participación de los medios de comunicación, que no se ha reducido a informar tomando en cuenta únicamente una fuente, no sólo les ha dado mayor protagonismo, sino que los ha convertido en mecanismos "públicos" de control de la actividad de "árbitros y jugadores". Pero, además, se ha generado otra dinámica de control interpartidista. Una de las características por las que deberá ser recordado este proceso electoral será la cantidad de demandas de unos partidos contra otros, acusándose mutuamente por violar alguna parte de la legislación electoral. De continuar una dinámica de este tipo, puede favorecer el que los partidos no se sientan como pudiendo hacer cualquier cosa para ganar, como estando por encima de la ley. Los partidos tenderían a ser más cuidadosos por la amenaza de que el resto de partidos lo están vigilando. Ello es bueno, aunque, indudablemente, no será suficien- 
te mientras en el Tribunal Supremo Electoral, la máxima autoridad en materia electoral, prevalezcan los intereses partidistas por encima del interés general. El Tribunal Supremo Electoral necesita ser autónomo, no sólo de cualquier poder del Estado, sino también de los partidos mismos.

\section{Algunos procesos sociales son cíclicos}

El planteamiento de que el proceso político salvadoreño de consolidación del régimen instaurado a raíz de los acuerdos de paz pueda estar llegando a una fase de agotamiento del entramado institucional diseñado en tales acuerdos nos puede alertar sobre dos cosas relacionadas. En primer lugar, que los procesos sociales (en este caso político) no son necesariamente irreversibles $y$, por tanto, tampoco son lineales, en el sentido de que una vez superada una etapa no hay posibilidades de retorno. En segundo lugar, que puede haber otro tipo de procesos como los cíclicos. Desde este punto de vista, valdría la pena que los principales actores del proceso político salvadoreño revisaran la lectura que hacen y consideraran la posibilidad de que nuestra historia política, hasta la fecha, también puede ser leída en términos de ciclos políticos. Entonces, ya no hablaríamos de agotamiento, sino de fin de un ciclo. Después podrá discutirse si el proceso es tan cíclico que es un constante repetir etapas o si se trata de un proceso en espiral, donde aunque los acontecimientos y las lógicas políticas sean parecidas (y se pueda creer que se está repitiendo una etapa que se creía ya superada), en realidad se trata de una fase superior. La existencia de procesos cíclicos se registra en ámbitos como la naturaleza y la religión. Un ejemplo de ciclos en la naturaleza nos lo proporciona el constante suceder de las estaciones lluviosa y seca, el movimiento de la tierra alrededor de su eje y también su movimiento alrededor del sol. En el ámbito de la religión nos encontramos, por ejemplo, con el Ilamado calendario litúrgico y la celebración, todos los años, de las mismas fiestas religiosas. Pero también se registran ciclos en el ámbito político. Por ejemplo, la celebración misma de elecciones cada cierto tiempo define ciclos electorales. El tiempo de duración de los períodos presidenciales también define ciclos políticos. Así que no conviene desechar la idea de ciclos políticos. De hecho, si recorremos la historia política salvadoreña es posible definir claramente ciclos políticos, que sugieren un movimiento de liberalización política, seguida de regresiones autoritarias.
El periodo que va de 1824 a 1838 - 1840 corresponde a la existencia en Centroamérica de la república federal, impulsada por los liberales. El periodo que va de 1840 a 1871 se puede interpretar como la primera regresión política salvadoreña (y centroamericana también), puesto que los conservadores vuelven al poder. Algunos historiadores llaman a este periodo la restauración conservadora. Estamos, pues, ante un primer reflujo. Entre 1871 y 1931, vuelven los liberales al poder e incluso hay un movimiento de "gobiernos de generales" a "gobiernos de los civiles". Otra vez pareciera "avanzar" el país, pero el periodo que va de 1931 a 1944, bajo una dictadura militar personalista, supone un nuevo retroceso, una nueva liberalización frustrada. El fin del régimen del general Maximiliano Hernández Martínez, en 1944, abre nuevas expectativas de democratización, pero hacia 1948, la liberalización (como paso previo a una democratización) es nuevamente truncada. La institución militar se instala en el poder. Situación que se prolongaría hasta 1979. Este año puede considerarse como de inicio de la transición política o el cambio de régimen que culminaría con la firma de los acuerdos de paz en México, en 1992, y terminaría con la instalación de las primeras autoridades políticas, elegidas democráticamente, en 1994.

Esta apretada presentación de la historia política salvadoreña contextualiza el proceso político iniciado en 1994 y que en el año 2000 pareciera estar perdiendo impulso, haciendo verosímil la hipótesis de la reversión. Esta no resultaría ajena a nuestra historia política. Pero, ino existe manera de evitarla? ¿Estamos determinados por nuestra historia y se nos hace imposible recorrer nuevos senderos? Si tomamos en cuenta que los esfuerzos democratizadores no sólo se han visto frustrados en El Salvador, sino que también en otros países de América latina, incluyendo países grandes como Argentina y Brasil, el cuadro se vuelve aún más pesimista.

Como lo señalé en líneas anteriores, no ha sido mi propósito culpar a nadie en este comentario. No creo que una actitud tal sea constructiva. Sin embargo, he tratado de llamar la atención sobre algunos acontecimientos que, interpretados desde una perspectiva cíclica de los procesos sociales, no deberían ser ignorados por todos aquellos actores políticos, si no con vocación democrática, al menos preocupados por la consolidación de un régimen democrático en el país. El costo humano de todos los anteriores intentos fallidos debería ser 
considerado como suficientemente alto como para tolerar otro fracaso. Una gran dosis de energía, expresada en voluntad política, será necesaria para impedir el torcimiento de lo comenzado desde 1992. Tal vez aún estemos a tiempo para ello y quizá será necesaria - por desgracia, por lo que ello significa respecto a la propia capacidad interna para valernos por nosotros mismos- una atenta observación extranjera sobre las votaciones del 12 de marzo y el respeto total de sus resultados, por parte de quienes los consideren adversos. Oja- lá no se produzca una parálisis institucional en el momento poselectoral, lo cual sería signo inequívoco del agotamiento al que aquí he hecho referencia. Si no se produce esa parálisis, ojalá que tampoco haya que esperar otro proceso electoral para corregir lo que haya que corregir para evitar vivir con la amenaza permanente de una posible reversión política.

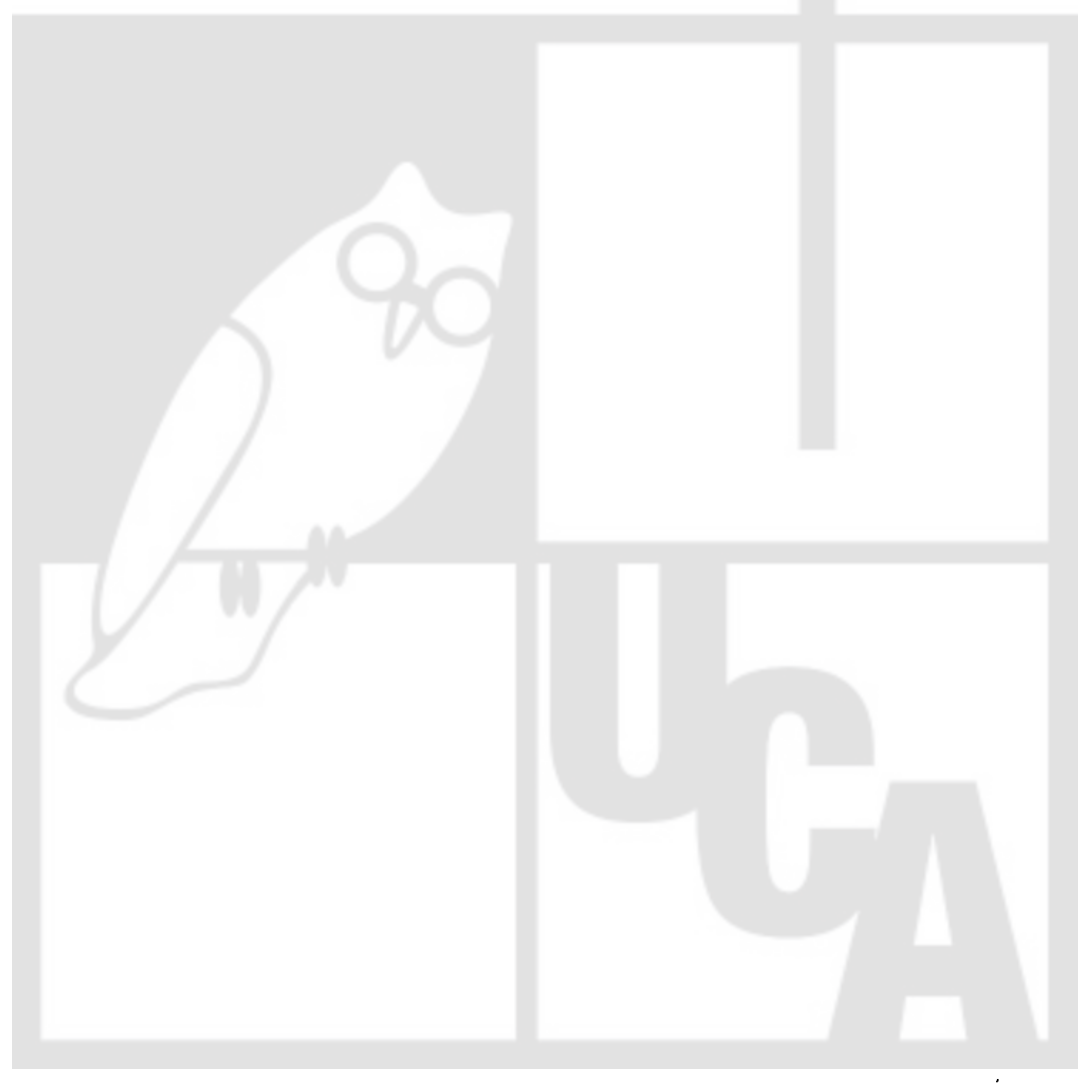

